\title{
ARAŞTIRMA / RESEARCH \\ Ortopedik cerrahi sonrası erken dönem hastane mortalitesi ve etki eden faktörler
}

\author{
Early period hospital mortality after orthopedic surgery and affecting factors
}

Salih Beyaz 1 iD

${ }^{1}$ Başkent Üniversitesi Adana Dr. Turgut Noyan Uygulama ve Araştırma Merkezi Ortopedi ve Travmatoloji Anabilim Dalı, Adana, Turkey

\begin{abstract}
Purpose: The aim of this study was to determine the factors affecting the mortality and the orthopedic surgical procedure with the highest hospital mortality.

Materials and Methods: 19,727 patients who had undergone orthopedic surgery between 1998-2016 were included in the study. Of these patients, 370 patients who died in the hospital within the first 30 days were screened. Surgical procedures for patients with a higher than average mortality, age, gender, presence of malignancy, history of coronary artery disease, diabetes, hemodialysis, cerebrovascular event history, presence of hypertension, The American Society of Anesthesiologists (ASA) assessment score and anesthesia patterns were recorded. Results: Of 19,727 patients undergoing orthopedic surgery, $237(1.23 \%)$ patients died early in the hospital after surgery. 4 surgical procedures with the highest mortality rate; It was found $6.35 \%$ in amputation surgery, $5.2 \%$ in femoral neck fracture, $4.2 \%$ in intertrochanteric hip fracture and $2.6 \%$ in vertabra surgery. Factors affecting the mortality were age, male gender, hypertension, having general anesthesia, having amputation surgery and having hemodialysis. ASA score was statistically significant in mortality all surgical types.

Conclusion: Amputation is the most deadly orthopedic surgery in the early period. comorbid chronic diseases are the most important factors affecting mortality in orthopedic surgery.
\end{abstract}

Cukurova Medical Journal 2019;44(3):977-983.

Keywords: Orthopedic surgery, mortality, amputation, hip fracture
$\mathrm{Ö}_{\mathrm{z}}$

Amaç: Çalışmamızın amacı erken dönem en yüksek hastane mortalitesine sahip ortopedik cerrahi prosedürü ve mortalite üzerine etki eden faktörleri saptamaktır.

Gereç ve Yöntem: 1998-2016 ylları arasında ortopedik cerrahi geçirmiş 19.727 hasta çalışmaya dahil edildi. Bu hastalardan ameliyat sonrası dönemde ilk 30 gün içinde hastanede ölen 370 hastanın dosyası tarandı. Genel mortalite ortalamasının üzerinde olan hastalara uygulanan cerrahiler, yaş, cinsiyet, malignite varlı̆̆1, koroner arter hastalığ1 öyküsü, diyabet, hemodiyaliz, geçirilmiș serebrovasküler olay öyküsü, hipertansiyon varlığ1 ASA değerlendirme skoru ve anestezi şekilleri kaydedildi.

Bulgular: Ortopedik cerrahi geçiren 19.727 hastadan 237 (\%1.23) hastanın cerrahi sonrası erken dönem hastanede öldüğü saptadık. Mortalitesi en yüksek 4 cerrahi prosedür; ampütasyon cerrahisinde $\% 6.35$, femur boyun kırı̆gnda $\% 5.2$, intertrokanterik kalça kırı̆ıında \%4.2, vertebra cerrahisinde \%2.6 olarak bulundu. Mortalite üzerine etki eden faktörler ampütasyon cerrahisi yapılan hastalarda yaș, erkek cinsiyet, hipertansiyon, ameliyatın genel anestezi altında yapılması, ve hastanın hemodiyalize giriyor olması, Yüksek ASA skorunun tüm cerrahi türlerinde istatistiksel olarak anlamlı bulundu.

Sonuç: İleri yaş ve buna bağlı ek kronik hastalıklar, ortopedik cerrahi gerektiren hastalarnn mortalitesini etkilemektedir. Ampütasyon cerrahisi, ve bu cerrahiye sebep olan nedenlerden dolayı, mortalitesi en yüksek ortopedik cerrahidir.

Anahtar kelimeler: Ortopedik cerrahi, mortalite, ampütasyon, kalça kırı̆̆ı

Yazışma Adresi/Address for Correspondence: Dr. Salih Beyaz, Başkent Üniversitesi Adana Dr. Turgut Noyan Uygulama ve Araştırma Merkezi Ortopedi ve Travmatoloji Anabilim Dalı, Adana, Turkey, E-mail: salihbyz@yahoo.com

Geliş tarihi/Received: 17.10.2018 Kabul tarihi/Accepted: 15.02.2019 Çevrimiçi yayın/Published online: 07.09.2019 


\section{GİRİ̧̧}

Yüm dünyada ortopedik cerrahiye gerensinim duyan hasta sayısı yıldan yıla artmaktadır ${ }^{1}$. Uygulanan cerrahiler kas iskelet sistemindeki dejenarasyon ve yaşlanma bağlı nedenlerden dolayıdır. İlerleyen yaşa bağlı olarak bu hastalarda komorbid hastalıklara daha fazla rastlanmaktadır. Ortopedik cerrahi sonrası erken dönem hastane mortalitesi hastanın kronik hastalıklarına ve ameliyat sonrası dönemde immobilizasyonuna bağlı olduğunu gösteren yayınlar mevcuttu ${ }^{2,3}$. Bu yayınlarda kalça kırı̆̆ı nedeniyle opere edilen hastaların mortalitesinin daha fazla olduğunu göstermektedir. Kalça kırığı daha sıklıkla osteporozun komplikasyonu olarak gelişen patolojik bir kırıktır. Senil osteoporoz daha çok ileri yaş hastalığı olarak bilinir. Ancak yayınlanan makalelerde amputasyon cerrahisi uygulanan hastalar çalsşmaya dahil edilmemiştir. Amputasyon cerrahisinin travma diş1 bilinen en sik nedeni ise diyabettir. Beyaz ve ark. diyabetin periferik komplikasyonlarından dolayı büyük kemik amputasyonu yapılan hastaların ilk 30 günde mortalite oranı $\% 16$ olarak bildirilmiştir 4 . Ortaya ç1kan erken dönem mortalitenin cerrahi gereksinimini ortaya çıkaran nedenleremi yoksa cerrahiye bağlı komplikasyonamı bağlı olduğu net değildir.

Çalıșmamızın amacı en yüksek oranda erken dönem hastane mortalitesine sahip ortopedik cerrahi prosedürü ve mortalite üzerine etki eden faktörleri saptamaktır.

\section{GEREÇ VE YÖNTEM}

Çalışma için 27/07/2017 tarihinde KA17/208 say1 numarası ile Başkent Üniversitesi Tıp Fakültesi Araştırma ve Etik kurul onayı alınmıştır. 1998-2016 yılları arasında Başkent Eğitim ve Uygulama Merkezi Hastanesinde ortopedik cerrahi geçirmiş 19,727 hasta çalışmaya dahil edildi. Günübirlik cerrahi uygulanan hastalar (karpal tünel sendromu, trigger finger etc.) çalışmaya dahil edilmedi. Bu hastalardan ameliyat sonrası dönemde ilk 30 gün içinde hastanede ölen 370 hastanın dosyası tarand. Cerrahi sonrası ilk 30 gün gün erken dönem olarak adlandırılmaktadır ve gelişen mortalitenin cerrahi ile direkt olarak ilişkili olduğunun varsayılmaktadır ${ }^{5}$. Politravmalı 76 hasta, elektrik veya alev yanığı olan 32 hasta, ateşli silah yaralanması olan 17 hasta çalışma dışı birakıldı. Çalışmaya 237 hasta dahil edildi. Genel mortalite ortalamasının üzerinde olan cerrahiler çalışmaya alındı. Bu hastaların tanıları, yaş, cinsiyet, malignite varlığ1, koroner arter hastalığ1 öyküsü, Diabetes Mellitus (DM), Hemodiyaliz (HD), Serebrovasküler olay (SVO) öyküsü, Hipertansiyon (HT) varllğ1 Amerikan Anestezistler Birliği (ASA) değerlendirme skoru ve anestezi şekilleri kaydedildi.

Hastanemizdeki rutin uygulamada operasyon öncesi tüm hastalar anestezist tarafindan değerlendirilmekte ve "Preoperatif değerlendirme formu" doldurulmaktadır. Elde edilen veriler için ameliyat öncesi anestezi değerlendirme formu, hastanın kullanmakta olduğu ilaç listesi ve hasta yatış öyküsü esas alınd. Takibi hastanemizde olan hastaların komorbid hastalıklarının teyidi için hasta dosyaları incelendi. Hastaneye başvuruları sırasında girilmesi zorunlu olan International Code Disease (ICD) sisteminden faydalanıldı. İlgili bölümce teyidi (örneğin HT için nefroloji veya kardiyoloji, SVO için nöroloji) yapılamayan hastalıklar gözardı edildi.

Karşılaștırma için kontrol grubuna SPSS windows version 24.0 tarafindan aynı hastalığa sahip, hastaneden taburcu edilen hasta listesi içerisinden randomize olarak seçildi. Ampütasyon cerrahisi uygulanmış 150 hasta, İntertrokanterik femur kırı̆̆1 olan 50 hasta, femur boyun kırı̆g olan 37 hasta vertebra cerrahisi uygulanan 21 hasta çalışmaya dahil edilmiștir.

\section{İstatistiksel analiz}

Sürekli değișkenlerin dağılımının normalliği Shaphiro Wilk testi ile test edildi. Normal dağılım gösteren iki bağımsız değişken grubunun karşılaştırılmasında Student $\mathrm{t}$ testi kullanıldı. Kategorik değişkenler arasındaki ilișkiyi değerlendirmek için ki-kare testi uygulandı. Tek değişkenli analize göre anlamlı değişkenler çok değişkenli analize dahil edildi. Mortalite için risk faktörünü belirlemek ve OR'leri ve \% 95 CI'leri tahmin etmek için Çok Değişkenli İkili Lojistik Regresyon analizi yapild. İstatistiksel analiz SPSS for Windows sürüm 24.0 ile yapıldı ve P değeri $<0.05$ kabul edildi.

\section{BULGULAR}

Ortopedik cerrahi geçiren 19.727 hastadan 237 (\%1.23) hastanın cerrahi sonrası erken dönem hastanede öldüğü saptadık. Mortalitesi en yüksek 6 cerrahi prosedür; ampütasyon cerrahisinde $\% 6.35$ (2016 hastanın 126 s1), intertrokanterik kalça kırığında \%4.2 (1089 hastanın 46'sı), femur boyun kirı̆ğnda $\% 5.2$ (649 hastadan 34'ü), vertebra cerrahisinde \%2.6 
(616 hastadan 16's1), total kalça artroplasinde (TKA) $\% 1.09$ (730 hastadan 8'i) ve total diz artroplastisinde (TDA) ise \%0.15 (1962 hastadan 3’ü) olarak saptand (Tablo 1). TKP ve TDP yapilan hastalarin mortalite düzeyi genel ortalamanın altında olduğundan dolayı değerlendirmeye alınmadı.

Mortalite üzerine etki eden faktörler ampütasyon cerrahisi yapılan hastalarda yaş $(p=0.001)$ erkek cinsiyet $\quad(p=0.003)$ hipertansiyon $\quad(p=0.004)$ ameliyatın genel anestezi altında yapılmasi $(\mathrm{p}=0.018)$ ve hastanın HD giriyor olmas1 $(p=0.02)$, Intertrokanterik kırı̆ğ olan hastalarda ise geçirilmiş SVO $(p=0.02)$ ve genel anestezi $(p=0.025)$, femur boyun kırı̆g tanısıyla cerrahi uygulanan hastalarda yapilan hastalarda yaş $(\mathrm{p}=0.043)$, hastanın daha önce tanı konulmuş malignite varlığ1 $(\mathrm{p}=0.042)$, HT $(p=0.001) \mathrm{KOAH}(\mathrm{p}=0.014)$ ve hastanin genel anestezi almasi $(p=0.001)$, vertebra cerrahisi geçiren hastalarda ise erkek cinsiyet $(p=0.001)$ mortalite üzerine etkin faktör olarak saptandı (Tablo 2).

Modellerin mortaliteyi açıklama oranları ise ampütasyon cerrahisi yapılan hastalarda \% 42.7, intertrokanterik kırıklarda \%24.7, parsiyel kalça protezinde $\% 55.7$, vertebra cerrahisi grubunda $\% 36.7$ olmuştur.

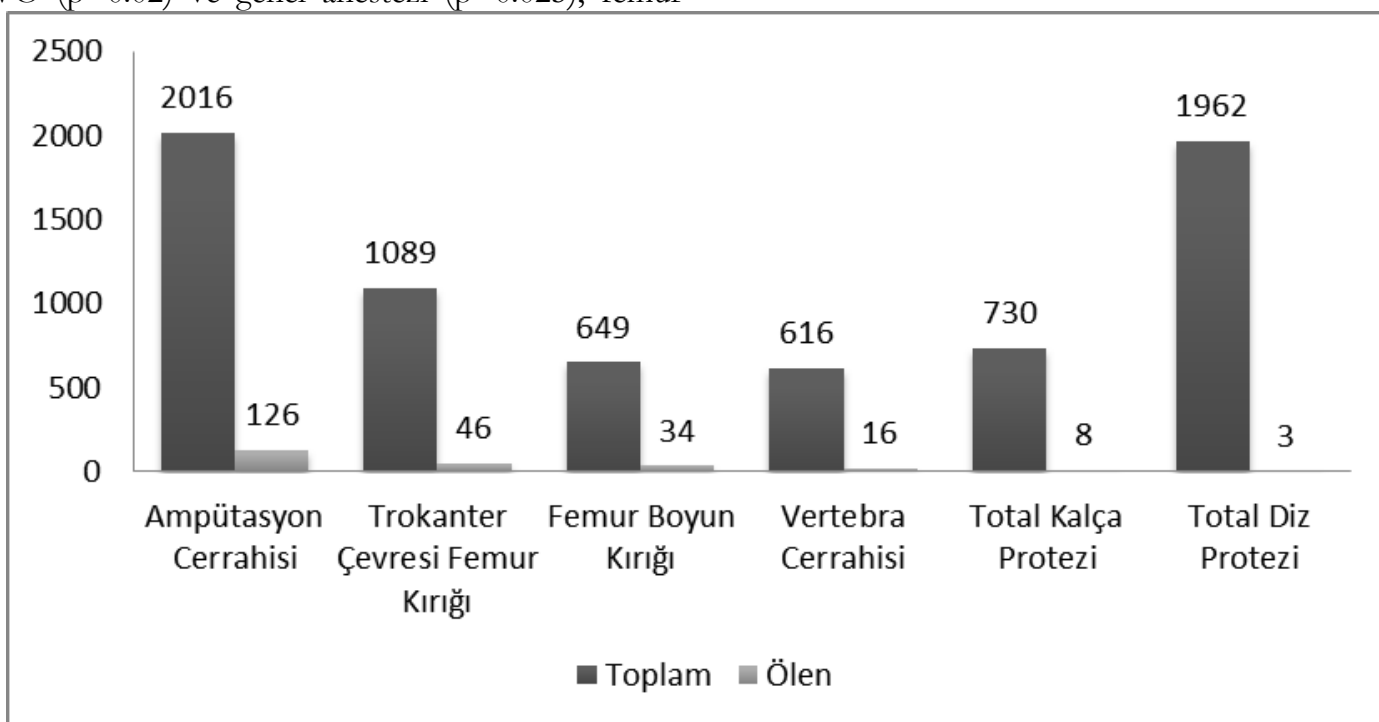

Şekil 1. Ortopedik cerrahi sonrası erken dönemde hastanede ölen hastaların cerrahilere göre dağılımı

Tablo 2:.Elde edilen univariate analiz sonuçları

\begin{tabular}{|c|c|c|c|c|c|c|c|c|c|c|c|c|}
\hline \multirow[t]{2}{*}{ Faktör } & \multicolumn{2}{|c|}{$\begin{array}{l}\text { Amputasyon } \\
\text { Cerrahisi }\end{array}$} & \multirow[b]{2}{*}{$\mathrm{p}$} & \multicolumn{2}{|c|}{$\begin{array}{l}\text { İntertorkanterik } \\
\text { Femur Kırığı }\end{array}$} & \multirow[b]{2}{*}{$\mathrm{P}$} & \multicolumn{2}{|c|}{$\begin{array}{l}\text { Parsiyel Kalça } \\
\text { Artoplastisi }\end{array}$} & \multirow[b]{2}{*}{ p } & \multicolumn{2}{|c|}{$\begin{array}{l}\text { Vertebra } \\
\text { Cerrahisi }\end{array}$} & \multirow[b]{2}{*}{$\mathrm{p}$} \\
\hline & $\begin{array}{l}\text { Ölen } \\
(\mathrm{n}=126)\end{array}$ & $\begin{array}{l}\text { Canlı } \\
(\mathrm{n}=150\end{array}$ & & $\begin{array}{l}\text { Ölen } \\
(\mathrm{n}=45)\end{array}$ & $\begin{array}{l}\text { Canl1 } \\
(\mathrm{n}=50)\end{array}$ & & $\begin{array}{l}\text { Ölen } \\
(\mathrm{n}=34)\end{array}$ & $\begin{array}{l}\text { Canl1 } \\
(\mathrm{n}=37)\end{array}$ & & $\begin{array}{l}\text { Ölen } \\
(\mathrm{n}=16)\end{array}$ & $\begin{array}{l}\text { Canli } \\
(\mathrm{n}=21)\end{array}$ & \\
\hline Yaş & $\begin{array}{l}67.59 \pm \\
11.78\end{array}$ & $\begin{array}{l}58.21 \pm \\
16.78\end{array}$ & $\begin{array}{l}0.001 \\
*\end{array}$ & $\begin{array}{l}70.64 \pm \\
11.12\end{array}$ & $\begin{array}{l}74.26 \\
\pm 9.12\end{array}$ & 0.217 & $\begin{array}{l}77.06 \pm \\
10.16\end{array}$ & $\begin{array}{l}71.76 \pm \\
11.35\end{array}$ & 0.043 & $\begin{array}{l}53.88 \\
\pm \\
21.78\end{array}$ & $\begin{array}{l}\text { 44.05 } \\
\pm \\
25.79\end{array}$ & 0.228 \\
\hline \multicolumn{13}{|l|}{ Cinsiyet } \\
\hline Erkek & $\begin{array}{l}62 \\
(\% 49.2)\end{array}$ & $\begin{array}{l}100 \\
(\% 66.7)\end{array}$ & $\begin{array}{l}0.003 \\
*\end{array}$ & $\begin{array}{l}23 \\
(\% 51.1)\end{array}$ & $\begin{array}{l}21 \\
(\% 42)\end{array}$ & 0.374 & $\begin{array}{l}13 \\
(\% 38.2)\end{array}$ & $\begin{array}{l}18 \\
(\% 48.6)\end{array}$ & 0.377 & $\begin{array}{l}11 \\
(\% 68.8 \\
)\end{array}$ & $\begin{array}{l}5 \\
(\% 23.8 \\
)\end{array}$ & $\begin{array}{l}0.006 \\
*\end{array}$ \\
\hline Kadin & $64(50.8)$ & $\begin{array}{l}50 \\
(\% 33.3)\end{array}$ & & $\begin{array}{l}22 \\
(\% 48.9)\end{array}$ & $\begin{array}{l}21 \\
(\% 42)\end{array}$ & & $\begin{array}{l}21 \\
(\% 61.8)\end{array}$ & $\begin{array}{l}19 \\
(\% 51.4)\end{array}$ & & $\begin{array}{l}5 \\
(\% 31.3 \\
)\end{array}$ & $\begin{array}{l}16 \\
(\% 76.2 \\
)^{2}\end{array}$ & \\
\hline \multicolumn{13}{|l|}{ Malignite } \\
\hline Var & $\begin{array}{l}10 \\
(\% 7.9)\end{array}$ & $\begin{array}{l}21 \\
(\% 14)\end{array}$ & 0.112 & $\begin{array}{l}19 \\
(\% 42.2)\end{array}$ & $\begin{array}{l}17 \\
(\% 34)\end{array}$ & 0.409 & $\begin{array}{l}7 \\
(\% 20.6)\end{array}$ & $\begin{array}{l}16 \\
(\% 43.2)\end{array}$ & $\begin{array}{l}0.042 \\
*\end{array}$ & $\begin{array}{l}8 \\
(\% 50)\end{array}$ & $\begin{array}{l}7 \\
(\% 33.3\end{array}$ & 0.306 \\
\hline Yok & $\begin{array}{l}116 \\
(\% 92.1)\end{array}$ & $\begin{array}{l}129 \\
(\% 86)\end{array}$ & & $\begin{array}{l}26 \\
(\% 57.8)\end{array}$ & $\begin{array}{l}32 \\
(\% 66)\end{array}$ & & $\begin{array}{l}27 \\
(\% 79.4)\end{array}$ & $\begin{array}{l}21 \\
(\% 56.8)\end{array}$ & & $\begin{array}{l}8 \\
(\% 50)\end{array}$ & $\begin{array}{l}14 \\
(\% 66.7\end{array}$ & \\
\hline Diyabet & & & & & & & & & & & & \\
\hline
\end{tabular}




\begin{tabular}{|c|c|c|c|c|c|c|c|c|c|c|c|c|}
\hline Var & $\begin{array}{l}99 \\
(\% 78.6)\end{array}$ & $\begin{array}{l}110 \\
(\% 73.3)\end{array}$ & 0.312 & $\begin{array}{l}13 \\
(\% 28.9)\end{array}$ & $\begin{array}{l}16 \\
(\% 32)\end{array}$ & 0.742 & $\begin{array}{l}9 \\
(\% 26.5)\end{array}$ & $\begin{array}{l}8 \\
(\% 21.6)\end{array}$ & 0.632 & $\begin{array}{l}6 \\
(\% 37.5\end{array}$ & $\begin{array}{l}7 \\
(\% 33.3\end{array}$ & 0.793 \\
\hline Yok & $\begin{array}{l}27 \\
(\% 21.4)\end{array}$ & $\begin{array}{l}40 \\
(\% 26.7)\end{array}$ & & $\begin{array}{l}32 \\
(\% 71.1)\end{array}$ & $\begin{array}{l}34 \\
(\% 68)\end{array}$ & & $\begin{array}{l}25 \\
(\% 73.5)\end{array}$ & $\begin{array}{l}29 \\
(\% 78.4)\end{array}$ & & 10 & 14 & \\
\hline \multicolumn{13}{|c|}{$\begin{array}{l}\text { Koroner } \\
\text { arter hastalı̆ } 1\end{array}$} \\
\hline Var & $\begin{array}{l}76 \\
(\% 60.3)\end{array}$ & $\begin{array}{l}89 \\
(\% 59.3)\end{array}$ & 0.868 & $\begin{array}{l}11 \\
(\% 25)\end{array}$ & $\begin{array}{l}16 \\
(\% 32)\end{array}$ & 0.454 & $\begin{array}{l}14 \\
(\% 42.4)\end{array}$ & $\begin{array}{l}13 \\
(\% 35.1)\end{array}$ & 0.532 & $\begin{array}{l}1 \\
(\% 6.3)\end{array}$ & $\begin{array}{l}4 \\
(\% 19)\end{array}$ & 0.241 \\
\hline Yok & $\begin{array}{l}50 \\
(\% 39.7)\end{array}$ & $\begin{array}{l}61 \\
(\% 40.7)\end{array}$ & & $\begin{array}{l}33 \\
(\% 75)\end{array}$ & $\begin{array}{l}34 \\
(\% 68)\end{array}$ & & $\begin{array}{l}19 \\
(\% 57.6)\end{array}$ & $\begin{array}{l}24 \\
(\% 64.9)\end{array}$ & & $\begin{array}{l}15 \\
(\% 93.8\end{array}$ & $\begin{array}{l}17 \\
(\% 81)\end{array}$ & \\
\hline \multicolumn{13}{|c|}{$\begin{array}{l}\text { Hipertansiyo } \\
\mathrm{n}\end{array}$} \\
\hline Var & $\begin{array}{l}112 \\
(\% 88.9)\end{array}$ & $\begin{array}{l}113 \\
(\% 75.3)\end{array}$ & $\begin{array}{l}0.004 \\
*\end{array}$ & $\begin{array}{l}28 \\
(\% 62.2)\end{array}$ & $\begin{array}{l}28 \\
(\% 56)\end{array}$ & 0.538 & $\begin{array}{l}28 \\
(\% 82.4)\end{array}$ & $\begin{array}{l}12 \\
(\% 32.4)\end{array}$ & $\begin{array}{l}0.001 \\
*\end{array}$ & $\begin{array}{l}8 \\
(\% 50)\end{array}$ & $\begin{array}{l}9 \\
(\% 42.9\end{array}$ & 0.666 \\
\hline Yok & $\begin{array}{l}14 \\
(\% 11.1)\end{array}$ & $\begin{array}{l}37 \\
(\% 24.7)\end{array}$ & & $\begin{array}{l}17 \\
(\% 37.8)\end{array}$ & $\begin{array}{l}22 \\
(\% 44)\end{array}$ & & $\begin{array}{l}6 \\
(\% 17.6)\end{array}$ & $\begin{array}{l}25 \\
(\% 67.6)\end{array}$ & & $\begin{array}{l}8 \\
(\% 50)\end{array}$ & $\begin{array}{l}12 \\
(\% 57.1\end{array}$ & \\
\hline \multicolumn{13}{|c|}{$\begin{array}{l}\text { Geçirilmiş } \\
\text { SVO }\end{array}$} \\
\hline Var & $\begin{array}{l}17 \\
(\% 13.5)\end{array}$ & $\begin{array}{l}22 \\
(\% 14.7)\end{array}$ & 0.78 & $\begin{array}{l}5 \\
(\% 11.1)\end{array}$ & $\begin{array}{l}19 \\
(\% 38)\end{array}$ & $\begin{array}{l}0.003 \\
*\end{array}$ & $\begin{array}{l}7 \\
(\% 20.6)\end{array}$ & $\begin{array}{l}11 \\
(\% 29.7)\end{array}$ & 0.376 & 0 & $\begin{array}{l}2 \\
(\% 9.5)\end{array}$ & 0.125 \\
\hline Yok & $\begin{array}{l}109 \\
(\% 46)\end{array}$ & $\begin{array}{l}128 \\
(\% 85.3)\end{array}$ & & $\begin{array}{l}40 \\
(\% 88.9)\end{array}$ & $\begin{array}{l}31 \\
(\% 62)\end{array}$ & & $\begin{array}{l}27 \\
(\% 79.4)\end{array}$ & $\begin{array}{l}26 \\
(\% 70.3)\end{array}$ & & $\begin{array}{l}16 \\
(\% 100)\end{array}$ & $\begin{array}{l}19 \\
)^{19} \% 0.5\end{array}$ & \\
\hline \multicolumn{13}{|c|}{$\mathrm{KOAH}$} \\
\hline Var & $\begin{array}{l}11 \\
(\% 8.7)\end{array}$ & $\begin{array}{l}20 \\
(\% 13.3)\end{array}$ & 0.228 & $\begin{array}{l}6 \\
(\% 13.3)\end{array}$ & $\begin{array}{l}10 \\
(\% 20)\end{array}$ & 0.386 & $\begin{array}{l}12 \\
(\% 35.3)\end{array}$ & $\begin{array}{l}4 \\
(\% 10.8)\end{array}$ & $\begin{array}{l}0.014 \\
*\end{array}$ & $\begin{array}{l}2 \\
\% 12.5\end{array}$ & $\begin{array}{l}2 \\
(\% 9.5)\end{array}$ & 0.125 \\
\hline Yok & $\begin{array}{l}115 \\
(\% 91.3)\end{array}$ & $\begin{array}{l}130 \\
(\% 86.7)\end{array}$ & & $\begin{array}{l}39 \\
(\% 86.7)\end{array}$ & $\begin{array}{l}40 \\
(\% 80)\end{array}$ & & $\begin{array}{l}22 \\
(\% 64.7)\end{array}$ & $\begin{array}{l}33 \\
(\% 89.2)\end{array}$ & & $\begin{array}{l}14 \\
(\% 87.5\end{array}$ & $\begin{array}{l}19 \\
(\% 90.5\end{array}$ & \\
\hline \multicolumn{13}{|c|}{ Hemodiyaliz } \\
\hline Var & $\begin{array}{l}56 \\
(\% 44.4)\end{array}$ & $\begin{array}{l}40 \\
(\% 26.7)\end{array}$ & $\begin{array}{l}0.002 \\
*\end{array}$ & $\begin{array}{l}12 \\
(\% 57.1)\end{array}$ & $\begin{array}{l}9 \\
(\% 42.9 \\
)^{9}\end{array}$ & 0.442 & $\begin{array}{l}6 \\
(\% 17.6)\end{array}$ & $\begin{array}{l}4 \\
(\% 10.8)\end{array}$ & 0.407 & $\begin{array}{l}3 \\
(\% 60)\end{array}$ & $\begin{array}{l}2 \\
(\% 9.5)\end{array}$ & 0.418 \\
\hline Yok & $\begin{array}{l}70 \\
(\% 55.6)\end{array}$ & $\begin{array}{l}110 \\
(\% 73.3)\end{array}$ & & $\begin{array}{l}33 \\
(\% 45.2)\end{array}$ & $\begin{array}{l}40 \\
)^{(\% 54.8} \\
\end{array}$ & & $\begin{array}{l}28 \\
(\% 82.4)\end{array}$ & $\begin{array}{l}33 \\
(\% 89.2)\end{array}$ & & $\begin{array}{l}13 \\
(\% 40.6 \\
)^{2}\end{array}$ & $\begin{array}{l}19 \\
)^{1 \% 90.5} \\
\end{array}$ & \\
\hline \multicolumn{13}{|l|}{ ASA } \\
\hline 1 & $0(\% 0)$ & $0(\% 0)$ & & $0(\% 0)$ & $0(\% 0)$ & & $0(\% 0)$ & $0(\% 0)$ & & $0(\% 0)$ & $0(\% 0)$ & \\
\hline 2 & $\begin{array}{l}10 \\
(\% 7.9)\end{array}$ & $\begin{array}{l}44 \\
(\% 29.3)\end{array}$ & $\begin{array}{l}0.001 \\
*\end{array}$ & $\begin{array}{l}7 \\
(\% 15.6)\end{array}$ & $\begin{array}{l}19 \\
(\% 38)\end{array}$ & $\begin{array}{l}0.001 \\
*\end{array}$ & $3(\% 8,8)$ & $\begin{array}{l}12 \\
(\% 32.4)\end{array}$ & $\begin{array}{l}0.013 \\
*\end{array}$ & $\begin{array}{l}6 \\
(\% 37.5\end{array}$ & $\begin{array}{l}15 \\
(\% 71.4\end{array}$ & $\begin{array}{l}0.012 \\
*\end{array}$ \\
\hline 3 & $\begin{array}{l}69 \\
(\% 54.8)\end{array}$ & $\begin{array}{l}83 \\
(\% 55.3)\end{array}$ & & $\begin{array}{l}25 \\
(\% 55.6)\end{array}$ & $\begin{array}{l}30 \\
(\% 60)\end{array}$ & & $\begin{array}{l}24 \\
(\% 70.6)\end{array}$ & $\begin{array}{l}23 \\
(\% 62.2)\end{array}$ & & (\%)37.5 & 6 & \\
\hline 4 & $\begin{array}{l}47 \\
(\% 37.3) \\
\end{array}$ & $\begin{array}{l}23 \\
(\% 15.3) \\
\end{array}$ & & $\begin{array}{l}13 \\
(\% 28.9)\end{array}$ & $1(\% 2)$ & & $\begin{array}{l}7 \\
(\% 20.6) \\
\end{array}$ & $\begin{array}{l}2 \\
(\% 5.4)\end{array}$ & & $\begin{array}{l}4 \\
(\% 25)\end{array}$ & 0 & \\
\hline \multicolumn{13}{|c|}{ Anestezi } \\
\hline Genel & $\begin{array}{l}64 \\
(\% 51.2)\end{array}$ & $\begin{array}{l}101 \\
(\% 67.3)\end{array}$ & $\begin{array}{l}0.018 \\
*\end{array}$ & $\begin{array}{l}26 \\
(\% 57.8)\end{array}$ & $\begin{array}{l}20 \\
(\% 40)\end{array}$ & $\begin{array}{l}0.047 \\
*\end{array}$ & $\begin{array}{l}12 \\
(\% 35.3)\end{array}$ & $\begin{array}{l}28 \\
(\% 75.7)\end{array}$ & $\begin{array}{l}0.001 \\
*\end{array}$ & $\begin{array}{l}16 \\
(\% 100)\end{array}$ & $\begin{array}{l}21 \\
(\% 100)\end{array}$ & \\
\hline Spinal & $\begin{array}{l}51 \\
(\% 40.8)\end{array}$ & $\begin{array}{l}38 \\
(\% 25.3)\end{array}$ & & $\begin{array}{l}17 \\
(\% 37.8)\end{array}$ & $\begin{array}{l}30 \\
(\% 60)\end{array}$ & & $\begin{array}{l}22 \\
(\% 64.7)\end{array}$ & $\begin{array}{l}9 \\
(\% 24.3)\end{array}$ & & & & \\
\hline Blok & $10(\% 8)$ & $\begin{array}{l}11 \\
(\% 7.3)\end{array}$ & & $2(\% 4.4)$ & $0(\% 0)$ & & & & & & & \\
\hline
\end{tabular}

TARTIŞMA

Bhattacharryya ve arkadaşlarının yapmış oldukları ülke genelindeki hastanelerde opere edilmiş 43.215 hastayı taradıkları bir çalışmadan ortopedik cerrahi sonrası erken dönem hastane mortalitesi oranı $\% 0.92$ olarak bulunmuştur ${ }^{3}$. Çalışmamızda aynı oran $\% 1.23$ olarak saptadık. Bu yüksek mortalite oranının çalışmamıza günübirlik cerrahi yapılan hastaların dahi edilmemesine ve hastanemizin 3. Basamak sağlık kuruluşu olmasıyla ilişkili olduğunu düşünüyoruz. Daha önce yapılan çalışmalar ameliyat sonrası erken dönemde mortalitesi en yüksek olan cerrahi prosedürün \%5.9 ile kalça kırı̆ğ cerrahisi olarak 
saptanmıştır. Mortalite oranı devlet hastaneleri ile üniversite hastaneleri arasında değişkenlik göstermemektedir ${ }^{6}$. Ancak bizim çalışmamızda mortalite oranı en yüksek ortopedik cerrahi ampütasyon cerrahisi olarak saptanmıştır. Bu durum hastanemizin diyabetik ayak hasta grubunun yoğunluğundan veya daha önce yapılan çalışmalarda ampütasyon yapılan hasta grubunun çalışmalara dahil edilmemesinden kaynaklanabilir.

Kronik rahatsızlıklar ve özellikle DM ortopedik cerrahi sonrasi mortaliteyi ciddi anlamda etkilemektedir. Ortopedik cerrahinin kan şekeri dekompanse hale getirerek mortalite üzerine etki ettiği düşünülmektedir. Hastaların ameliyat öncesi dönemde kan șekeri regülasyonun mortalite ve morbidite üzerine etkin olduğu gösterilmiştir ${ }^{7}$. Çalışmamızda ampütasyon cerrahisi uygulanmış ve erken dönemde ölen 126 hastadan 99'unda (\%78) DM saptanırken bu oran intertorkanterik femur kırığında \%28 parsiyel kalça protezi yapılanlarda $\% 26.5$ vertebra cerrahisi yapilan hastalarda ise $\% 37.5$ olarak bulunmuştur. Ampütasyon cerrahisi uygulanan hastalarda travma dişı en önemli nedeni DM olmasından dolayı bu oranın çalışmamızda yüksek çıkmış olması literatür ile uyumludur. Ancak DM'un erken dönem hastane mortalitesine katkısı olduğunu saptamadik.

Kronik böbrek yetmezliği ampütasyon cerrahisi yapılan hastalarda erken dönem hastane mortalitesi için anlamlı bir risk faktörü olarak saptanırken diğer cerrahiler için mortalite'ye etkisi olmadığını bulduk. Kronik böbrek hastalığının bilinen en yaygın nedenlerinden biri DM'tur ${ }^{8}$. Diyabetik hastalarda ampütasyona neden olan ayak sorunları diyabet süresi ile ilintilidir’. Mikrovasküler düzeydeki sistemik değişiklikler aynı zamanda renal arteriolleride etkilemekte ve bu değişiklikler hastalarda kronik böbrek hastalığına neden olmaktadır ${ }^{10}$. Özellikle 10 yıldan uzun süredir diyabet tanısı ile tedavi gören hastalarda vasküler değişiklikler daha belirgin hale gelmektedir. Mikrovasküler değişiklikler nedeniyle ortaya çıkan ayak sorunları her on hastadan birinde ayak ülserlerine ve buna bağlı olarakta ampütasyonlara neden olmaktadır ${ }^{11}$. $\mathrm{Bu}$ süre ilişkisinden dolayı ampütasyon cerrahisi uygulanan hastalarda kronik böbrek sorunlarının mortaliteye etki etmesi beklenilen bir sonuçtur. Yapılan çalışmalarda $\mathrm{KBH}$ uzun dönemli kalça femur boyun kırı̆̆1 cerrahisi sonrasında mortalite'ye etki eden faktörlerden biri olduğu gösterilmiştir ${ }^{12}$.

Kardiyovasküler hastalıklar (Hipertansiyon, konjestif kalp yetmezliği, geçirilmiş myokard infarktüsü vb.) hastalıklar özellikler kalça kırığ1 cerrahisi sonras1 erken dönem mortalite üzerine en önemli risk faktörüdür ${ }^{13,14}$. Kardivasküler hastalığa sahip hastalarda hem alt ekstremite ampütasyon riski hemde postop dönemde mortalite oranı daha fazladır ${ }^{15}$. Çalışmamızda amputasyon cerrahisi uygulanan hastalarda mevcut koroner arter hastalığının mortalite üzerine etkisi saptanmaz iken, hipertansiyon öyküsünün olması ampütasyon ve femur boyun kırı̆gı cerrahisi sonrası mortalite'ye etki ettiğini saptadik.

Zuo ve arkadaşkarının yaptığı bir meta analizde, kalça kırığ1 nedeniyle cerrahi geçiren hastalara verilen anestezi türünün (genel vs spinal) erken dönem mortalite üzerine etkin olmadığını göstermiştir ${ }^{16}$. Rashid ve ark. yaptıkları bir çalışmada ise intertokanterik kalça kırı̆̆ı nedeniyle osteosentez yapılan hastalarda kullanılan anestezik yöntemin mortaliyete üzerine etkisi olmadığını saptamıştır ${ }^{17}$. Çalışmamızda ise hem ampütasyon cerrahisinde hemde kalça kırı̆g cerrahisinde anestezi türünün mortalite üzerine etkin olduğu saptadık. Ancak proksimal femur kırı̆̆ı olan hastalarda mortaliteyi etkilen önemli noktalardan biride hastanın kırık sonrası ne kadar sürede opere edildiğidir. Bizim çalışmamız bu veriye sahip değildir.

Kronik tıkayıcı akciğer hastalığı dünyada ölüme ve uzun dönemli sakatlığa neden ola hastalıklar arasında 3. sırada yer almaktadır ${ }^{18}$. Alex Gu ve ark. yaptığ1 çalıșmada revizyon total diz protezi ihtiyacı duyan kronik tıkayıcı akciğer hastalığına sahip hastaların ameliyat sonrası dönemde daha yüksek morbidite ve mortalite ile seyrettiklerini saptamıştır ${ }^{19}$. Çalışmamızda ise sadece femur boyun kırığı olan hastalarda mortalite üzerine etkin olduğu saptanmıştır. Bu durum femur boyun kırı̆ıının daha çok yaşlı hasta popülasyonunda görülmesi ve bu hastalara çimentolu parsiyel kalça protezi yapılmasıyla açıklanabilir. Çimentolu yapılan parsiyel kalça protezlerinde basınçlı çimento uygulaması sırasında emboli saptandığını gösteren yayınlar mevcuttur ${ }^{20,21}$.

ASA skorlamasi 1963 yilında kullanilmaya başlamıștır ${ }^{22}$. Anestezistler tarafidan hastanın ameliyat öncesi durumunu sorgulayarak ameliyat sonrası dönemde mortalite ve morbiditesini tahmin etmede kulanılan bir sinflama sistemidir ${ }^{23}$. Bizim çalıșmamızda da ASA skorunun artması erken dönem hastane mortalitesini tahmin etmede dört cerrahi yöntemde de etkin bir faktör olarak saptadık. Hastanın komorbid hastalıkları ve genel hasta 
kondüsyonu göz önüne alınarak yapılan bu skorlama erken dönem hastane mortalitesini en iyi saptayan metod olduğunu düşünüyoruz.

Yaş ve erkek cinsiyet ampütasyon cerrahisi uygulanan hastalar için bir risk faktörü olarak saptanırken diğer gruplarda saptanmamıştır. Travma dışı ampütasyon cerrahisi başlıca nedenleri diyabet ve periferik vasküler hastalıklardır. Erkek cinsiyette diyabete bağlı ayak sorunları kadınlarla kıyaslandığında daha fazla görülmektedir ${ }^{24}$. Bunun nedeni kadınların ayak bakımına erkeklere kıyasla daha çok dikkat etmeleridir ${ }^{24}$.

Ortopedik cerrahi geçiren hastaları standardize etmek mümkün değildir. Ayrıca çalışmamızın en büyük handikapı prospektif bir çalışma olmasıdır. Gelecekte planlanacak çalışmalarda mortaliteyi etkileyen nedenler kronik rahatsızlıklarının yanı sıra vücut kitle indeksi, hastaların alışkanlıkları (sigara, alkol vb) ve özellikle kırık cerrahisi geçiren hastalarda zamanlamanın çalışmaya dahil edilmesi daha değerli çalışmaların ortaya çıkmasına katkıda bulunacaktır. Bir diğer önemli kısıtlılık hastaların mortalite nedeninin belirlenememesidir. Ülkemizde rutin otopsi uygulamasının olmaması hastaların kesin ölüm nedeninin belirlenememesindeki en önemli nedendir.

Ampütasyon cerrahisi erken dönem hastane mortalitesi en yüksek ortopedik cerrahidir. Travma dışı ampütasyonun bir numaralı sebebi olan uzun süredir var olan diyabet ve periferik vasküler komplikasyonları bunun en önemli nedenidir. Proksimal femur kırı̆̆1 olan hastalarda ise altta yatan asıl sebebin osteoporoz olması ve daha çok ileri yaşta görülmesi erken dönem hastane mortalitesine etki etmektedir. Ortopedik cerrahinin kendisinden ziyade hastanın eșlik eden kronik hastalıklar ve hastanın yașı, erken dönem hastane mortalitesine etki eden en önemli faktörlerdir.

Yazar Katkıları: Çalışma konsepti/Tasarımı: SB; Veri toplama: SB; Veri analizi ve yorumlama: SB; Yazı taslağı: SB; İçeriğin eleştirel incelenmesi: $\mathrm{SB}$; Son onay ve sorumluluk: SB; Teknik ve malzeme desteği: SB Süpervizyon: SB; Fon sağlama (mevcut ise): yok.

Hakem Değerlendirmesi: Dıș bağımsız.

Çıkar Çatışması: Yazarlar çıkar çatışması beyan etmemişlerdir. Finansal Destek: Yazarlar finansal destek beyan etmemişlerdir. Author Contributions: Concept/Design : SB; Data acquisition: SB; Data analysis and interpretation: SB; Drafting manuscript: SB; Critical revision of manuscript: SB; Final approval and accountability: SB; Technical or material support: SB; Supervision: SB; Securing funding (if available): $\mathrm{n} / \mathrm{a}$.

Peer-review: Externally peer-reviewed.

Conflict of Interest: Authors declared no conflict of interest.

Financial Disclosure: Authors declared no financial support

\section{KAYNAKLAR}

1. Kadono Y, Yasunaga H, Horiguchi H, et al. Statistics for orthopedic surgery 2006-2007: data from the
Japanese Diagnosis Procedure Combination database. J Orthop Sci. 2010;15:162-170.

2. Menendez ME, Neuhaus V, Ring D. Inpatient mortality after orthopaedic surgery. Int Orthop. 2015;39:1307-14

3. Bhattacharyya T, Iorio R, Healy WL. Rate of and risk factors for acute inpatient mortality after orthopaedic surgery. J Bone Joint Surg. 2002;84-A:562-72.

4. Beyaz S, Guler UO, Bagir GS. Factors affecting lifespan following below-knee amputation in diabetic patients. Acta Orthop Traumatol Turc. 2017;51:39397.

5. Itani KM. Validation of the 30-Day postoperative mortality standard and its relevance. JAMA Surg. 2016;151:423.

6. Sheehan KJ, Sobolev B, Guy P, et al. In-hospital mortality after hip fracture by treatment setting. CMAJ. 2016;188:1219-25.

7. Shohat N, Foltz C, Restrepo C, Goswami K, Tan T, Parvizi J. Increased postoperative glucose variability is associated with adverse outcomes following orthopaedic surgery. Bone Joint J. 2018;100-B:112532.

8. Gansevoort RT, Correa-Rotter R, Hemmelgarn BR, et al. Chronic kidney disease and cardiovascular risk: epidemiology, mechanisms, and prevention. Lancet. 2013;382:339-52.

9. Alavi A, Sibbald RG, Mayer D, et al. Diabetic foot ulcers: Part I. Pathophysiology and prevention. J Am Acad Dermatol. 2014;70:1 e1-18.

10. Nasri H, Rafieian-Kopaei M. Diabetes mellitus and renal failure: Prevention and management. J Res Med Sci. 2015;20:1112-20.

11. Moulik PK, Mtonga R, Gill GV. Amputation and mortality in new-onset diabetic foot ulcers stratified by etiology. Diabetes Care. 2003;26:491-4.

12. Chow SK, Qin JH, Wong RM et al. One-year mortality in displaced intracapsular hip fractures and associated risk: a report of Chinese-based fragility fracture registry. J Orthop Surg Res. 2018;13:235.

13. Sennerby $U$, Melhus $H$, Gedeborg R, et al. Cardiovascular diseases and risk of hip fracture. JAMA. 2009;302:1666-73.

14. von Friesendorff M, McGuigan FE, Wizert A, et al. Hip fracture, mortality risk, and cause of death over two decades. Osteoporosis Int. 2016;27:2945-53.

15. Mundell BF, Luetmer MT, Kremers HM, Visscher S, Hoppe KM, Kaufman KR. The risk of major cardiovascular events for adults with transfemoral amputation. J Neuroeng Rehabil. 2018;15:58.

16. Zuo D, Jin C, Shan M, Zhou L, Li Y. A comparison of general versus regional anesthesia for hip fracture surgery: a meta-analysis. Int J Clin Exp Med. 2015;8:20295-301.

17. Rashid RH, Shah AA, Shakoor A, Noordin S. Hip fracture surgery: does type of anesthesia matter? BioMed Res Int. 2013;2013:252356.

18. Rycroft CE, Heyes A, Lanza L, Becker K. 
Epidemiology of chronic obstructive pulmonary disease: a literature review. Int J Chron Obstruct Pulmon Dis. 2012;7:457-494.

19. Gu A, Wei C, Maybee CM, Sobrio SA, Abdel MP, Sculco PK. The impact of chronic obstructive pulmonary disease on postoperative outcomes in patients undergoing revision total knee arthroplasty. J Arthroplasty. 2018;33:2956-60.

20. Christie J, Burnett R, Potts HR, Pell AC. Echocardiography of transatrial embolism during cemented and uncemented hemiarthroplasty of the hip. J Bone Joint Surg. 1994;76:409-12.

21. Donaldson AJ, Thomson HE, Harper NJ, Kenny
NW. Bone cement implantation syndrome. Br J Anaesth. 2009;102:12-22.

22. Keats AS. The Estimate of anesthetic risk in medical evaluations. Am J Cardiol. 1963;12:330-333.

23. Parenti N, Reggiani ML, Percudani D, Melotti RM. Reliability of American Society of Anesthesiologists physical status classification. Indian J Anaesth. 2016;60:208-14.

24. Amin L, Shah BR, Bierman AS, et al. Gender differences in the impact of poverty on health: disparities in risk of diabetes-related amputation. Diabetic Med.. 2014;31:1410-17. 